\title{
Urgences
}

\section{Jean-Marc Cormier, La symphonie déconcertante, Rimouski, Éditeq, 1984.}

\section{Danielle Bérubé}

Numéro 11, 3e trimestre 1984

URI : https://id.erudit.org/iderudit/025177ar

DOI : https://doi.org/10.7202/025177ar

Aller au sommaire du numéro

Éditeur(s)

Urgences

ISSN

0226-9554 (imprimé)

1927-3924 (numérique)

Découvrir la revue

Citer ce compte rendu

Bérubé, D. (1984). Compte rendu de [Jean-Marc Cormier, La symphonie

déconcertante, Rimouski, Éditeq, 1984.] Urgences, (11), 77-80.

https://doi.org/10.7202/025177ar

Ce document est protégé par la loi sur le droit d'auteur. L'utilisation des services d'Érudit (y compris la reproduction) est assujettie à sa politique d'utilisation que vous pouvez consulter en ligne.

https://apropos.erudit.org/fr/usagers/politique-dutilisation/
Cet article est diffusé et préservé par Érudit.

Érudit est un consortium interuniversitaire sans but lucratif composé de l'Université de Montréal, l'Université Laval et l'Université du Québec à Montréal. Il a pour mission la promotion et la valorisation de la recherche. https://www.erudit.org/fr/ 


\section{PARUTIONS COMMENTÉES}

LA SYMPHONIE DÉCONCERTANTE de Jean-Marc Cormier, EDITEQ, 1984

"Malheureux celui qui dans ses souvenirs d'enfance ne puise que tristesse et peur. Infortuné celui qu'étreint la noire mémoire d'heures solitaires.

Tel est le lot à moi imparti par les dieux.

(...) Vivre, c'est survivre à un enfant mort.

JE est un autre."

"Pour un peu de tendresse, je donnerais ma vie..." JeanMarc Cormier nous présente, dans la Symphonie déconcertante, six nouvelles où tout au long de chacune nous retrouvons la recherche de tendresse, de bonheur, d'affection... une quête qui, comme nous le verrons plus loin, sera infructueuse.

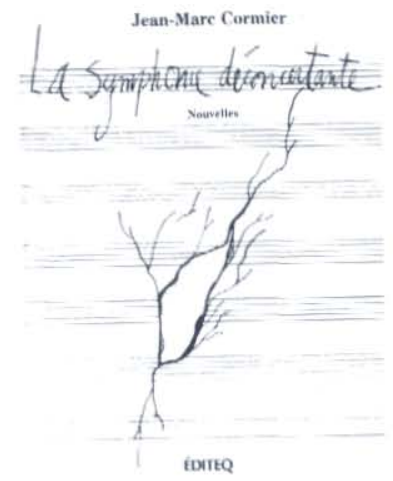

C'est aussi l'envers de la médaille du quotidien que l'auteur nous fait vivre en lecture (heureusement!). Les choses de tous les jours prennent une dimension extrême, fantasmagorique, fantastique, aussi. Le traitement des nouvelles nous suggère des liaisons entre l'absurde et la violence, entre la vie et la mort. 
Et puis, pour vous "en faire voir" davantage, voici une brève présentation de chaque nouvelle.

La première, "Le météorite" nous semble l'affabulation d'un mysticisme dans lequel s'environnent ou se tortillent trop souvent les artistes ou ceux qui se considèrent comme tel, parfois à tort.

Mais en résumé, c'est quand le ridicule tue... où on atteint une déchéance sans rémission sauf avec la mort "stupide" pour cette fameuse gloire posthume tant recherchée.

"(...) Les deux tounes gravées sur le premier quarantecinq tours de l'ex-super-vedette occupent déjà les deux premières places sur tous les palmarès et le plus beau reste à venir".

La seconde nouvelle: "L'Illusionissime" nous montre une réalité trop dure à supporter qui engendre l'absurdité par une violence inutile (y en a-t-il d'utile?). Elle exprime aussi que plus rien n'a de sens, même la vie qui ne sert plus à rien et que la seule issue intéressante est la mort. Une histoire d'illusions, d'illusions sur tout, sur tout un chacun.

"Marie-Madeleine était stone depuis plus de trois mois. Gelée dure jusqu'aux oreilles depuis qu'elle avait quitté le domicile paternel sur un coup de tête (...) avec un gars de bicycle qui l'avait amenée foirer dans un deux-et-demi crotté de la toilette au balcon...."

Les trois prochaines nouvelles du recueil constituent une séquence de même facture puisqu'elles parlent toutes les trois de l'enfance.

La première de la série, "Le gai Noël des étrangers" présente les étrangers aux yeux des enfants: les adultes. La xénophobie change d'allure. Elle devient plus restrictive car c'est toute la cellule familiale qui représente un CLAN hostile. Ici aussi, il y a une fuite possible: le rêve perpétuel, la schizophrénie. 
"Enfermé dans la pénombre palpable, humide et odorante de la boîte à bois aménagée sous l'escalier, le petit garçon était accroupi en chien de fusil (...) Et les étrangers se chamaillaient de la gueule devant deux tasses de thé froid..."

La deuxième de la séquence, "Le Navet bleu" traite des histoires de jeunesse qui tournent au drame parce qu'une certaine réalité devient indissociable du rêve puisqu'il faut, une fois de plus, fuir. Cette fois, c'est la peur qui cause la fuite.

"Ce fut une communion totale. J'ai dépecé Josephat Robert et je l'ai avalé (...) Pour survivre, nous avons fusionné."

La dernière nouvelle de la série "enfance", "Plainte désolée", exprime le dédoublement auteur-personnage. Un retour vers les lieux de son enfance pour mieux crever et aussi quand le métier d'écrivain ne nourrit plus (tout le monde sachant déjà cela...). Les personnages allongés sur le papier deviennent trop voraces. II faut alors s'en débarrasser à tout prix... "Le cauchemar à mots", en quelque sorte... ou n'est-ce pas plutôt la vie elle-même qui devient tout un cauchemar, pas seulement à mots?...

"Et puis la porte du seize s'était ouverte. Les autres locataires de l'immeuble, alertés parle hurlement (...) Ils ont vu, sur le pas de la porte, s'écrouler l'homme aux talons hauts, un couteau de cuisine en plein coeur."

La nouvelle finale du recueil, celle qui lui donne son titre, "La Symphonie déconcertante", nous raconte une histoire de télépathie. Un étrange télépathe devient perméable aux vécus de tout un chacun à un point tel, qu'il nous semble être une nouvelle espèce de CAMÉLÉON. Mais, vous le savez aussi bien que nous, le caméléon est une bête intéressante, tellement imprévisible, parfois embêtante, voire même dangereuse qu'il nous faut prendre garde de l'endroit où nous mettons les pieds ou les doigts...

"Je suis télépathe. Je venais de découvrir que j'étais télépathe. Et cela me faisait horriblement mal. Plus j'en étais 
conscient et plus se densifiait ce flot de pensées continu qui me pénétrait malgré moi..."

Plusieurs thèmes sont revenus tout au long des six nouvelles: la vie, la mort, l'absurde, la violence, la fuite, l'enfance, le rêve, etc... Tous ces thèmes nous tombent dessus, nous tournoient autour avec une même CONSTANTE: le mal d'exister où les fantasmes permettent de fuir, d'échapper à la réalité mais surtout de faire des efforts désespérés pour retrouver/trouver une parcelle d'affection et de tendresse. Cette quête du bonheur devient impossible, puisqu'à chaque détour, nous nous apercevons que la parcelle de tendresse attrapée au vol (ou même volée) n'était que dans la tête ou pire, mensonge. C'est cette quête, en somme, qui établit le grand espoir du recueil, un espoir caché mais un espoir tout de même... Mais cette quête est-elle vraiment si inatteignable, si incertaine comme veut nous le faire voir Jean-Marc Cormier? En ce qui me concerne, j'en doute.

La Symphonie déconcertante est destinée à être lue. Elle est captivante à lire... Dieu sait qu'elle serait absolument horrible à vivre...

Danielle Bérubé

LA MAISON TRESTLER, de Madeleine Ouellette-Michalska, Québec/Amérique, 1984.

Immédiatement après avoir achevé la lecture de La Maison Trestler, l'envie est bien grande de feuilleter le roman à rebours jusqu'à pouvoir répéter ces premiers mots de la narratrice: "Je ne sais plus comment cette histoire a commencé!"

En fait, si cette histoire est difficile à résumer, c'est qu'elle est à la fois celle d'une femme et DES FEMMES, d'un individu et d'une collectivité, d'une existence et d'une époque. Une histoire particulière qui se multiplie par l'interpénétration de plusieurs univers, réels (mais où est la réalité?) ou imaginaires. L'histoire d'un personnage en train de se constituer sous nos yeux, au fil de la lecture, née de l'imagination passionnée d'une romancière (personnage-narratrice) qui se 